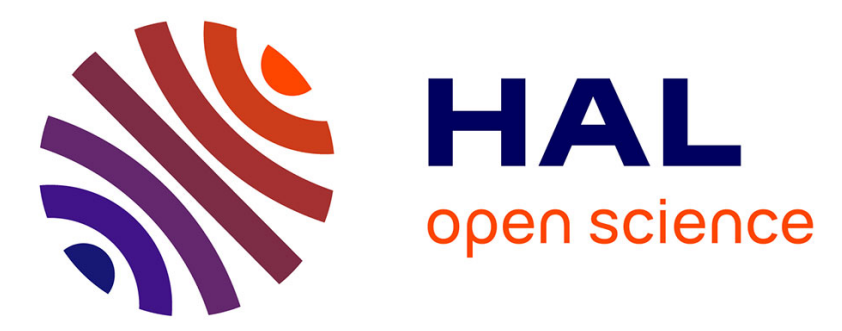

\title{
Hybrid finite element boundary element solutions for three dimensional scalar potential problems
}

Gérard Meunier, Jean-Louis Coulomb, Shape Salon, Laurent Krähenbühl

\section{To cite this version:}

Gérard Meunier, Jean-Louis Coulomb, Shape Salon, Laurent Krähenbühl. Hybrid finite element boundary element solutions for three dimensional scalar potential problems. IEEE Transactions on Magnetics, 1986, 22 (5), pp.1040- 1042. 10.1109/TMAG.1986.1064625 . hal-00359878

\section{HAL Id: hal-00359878 https://hal.science/hal-00359878}

Submitted on 9 Feb 2009

HAL is a multi-disciplinary open access archive for the deposit and dissemination of scientific research documents, whether they are published or not. The documents may come from teaching and research institutions in France or abroad, or from public or private research centers.
L'archive ouverte pluridisciplinaire HAL, est destinée au dépôt et à la diffusion de documents scientifiques de niveau recherche, publiés ou non, émanant des établissements d'enseignement et de recherche français ou étrangers, des laboratoires publics ou privés. 


\section{HYBRID FINTTE FLEMENT BOUNDARY ELEMENT SOLUTIONS FOR THRFR DIMENSIONAL SCAIJAR POTENTIAL PROBLEMS}

G. Meunier, J.L. Coulomb

Laboratoire d'Flectrotechnique

de Grenoble, France

L. Krahenbul

Ecole Central de tyon, France

\section{S.J. Salon}

RPI

Troy, New York

\section{Abstract}

The Hybrid finite element - boundary element method has been shown to be an effective and efficient method for the solution of two dimensional [1] and axisymetric [2] electromagnetic field problems. The method allows for any region in the problem to be represented by either finite elements or boundary elements. Thus the user can solve open boundary problems or certain classes of exterior problems [3] by using the boundary element method and still retain the nonlinear capability of the rinite element method for regions with nonlinear materials. The method is now exterded to three dimonsional scalar potential problems. An example is presented here for a three dimensional problem. The results were then compared to a closed form solution.

\section{Three Dimensional Formulation}

In the following formulation the unknown is the scalar potential, which is the solution of laplace's equation, in both the finite element and boundary element regions. This section gives the basis of the formulation for the finite elements and the boundary elements which was used on the example in the following section.

Finite Elemcnt Region: In the finite element region the unknown potential satisfies Laplace's equation. In Galerkin form this becomes

$$
\iiint_{\Omega}\left(\nabla^{2} \hat{\emptyset}\right)_{\mathrm{w}} \mathrm{d} \Omega+\iint\left(\frac{\partial \phi}{\partial \boldsymbol{n}}\right) \mathrm{wds}=0
$$

where is a weighting function and the new variable $\partial \emptyset / \hat{c} n$ appears only on the boundary of the problem. Expanding $\emptyset$ in terms of polynomials and choosing $w=\alpha_{i}$ we obtain for an element.

$$
s^{(e)} \emptyset+q=0
$$

Where

$$
\begin{aligned}
& s_{i j}=\iiint\left(\frac{\partial \alpha i}{\partial x} \frac{\partial \alpha i}{\partial x}+\frac{\partial \alpha i}{\partial y} \frac{\partial \alpha i}{\partial y}+\frac{\partial \alpha i}{\partial z} \frac{\partial \alpha \dot{i}}{\partial z}\right) d x d y d z \\
& q_{j}=\iint \frac{\partial \phi}{\partial n} \alpha j d s
\end{aligned}
$$

Boundary elements: Applying Green's theorem to Laplace's equation we obtain an expression for the potential in terms of the potential and its normal derivative on the boundary.

$$
\gamma \emptyset=-\iint\left(\emptyset \frac{\partial G}{\partial n}+G \frac{\partial \emptyset}{\partial n}\right) d s
$$

Where $\gamma=1$ for a point inside the region $\gamma=0$ for a point outside the region $\gamma=$ the fraction of the internal angle made by the surface at the field point. (e.g. 0.5 if the point is on a straight line)

This expression is evaluated directly by the point matching method. Gauss quadrature is used to perform the integration.

Assembly of the matrix: In symbolic form the system matrix is as follows

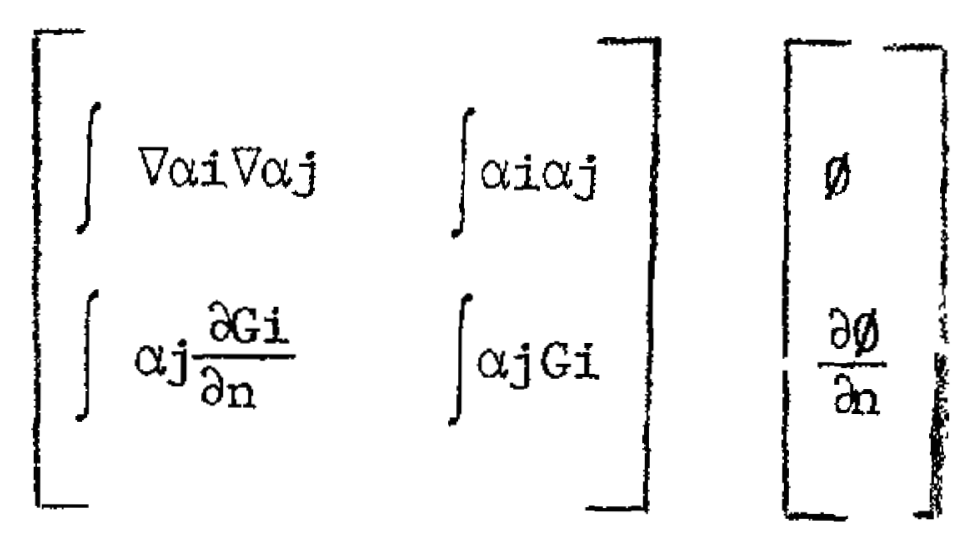

where the unknown $\emptyset$ exists at each node point and the unknown $\partial \not / \partial n$ exists at each node on the boundary.

Example problem: In order to verify the formulation, an example was taken from electrostatics. The example chosen was a conducting sphere having an applied potential. The sphere is imbeded in uniform homogeneous space. The region in between the sphere and an arbitrarily chosen cube was represented by finite elements. In this case the finite elements were tetrahedra and were generated by the Delauny method [4], the boundary elements were the triangular faces of the tetrahedra which were in common with the exterior cube. See figure 1.

Matrix solution. The system matrix has the form shown below in figure 2. It should be pointed out that while the finite element equations are sparse, the boundary element equations are in general fully populated, i.e. all unknowns on the boundary are coupled to each other. Another point influencing the choice of a solution technique is that the boundary element equations will generally be nonsymetric. The method chosen in this case was the preconditioned biconjugate gradient method [5]. 


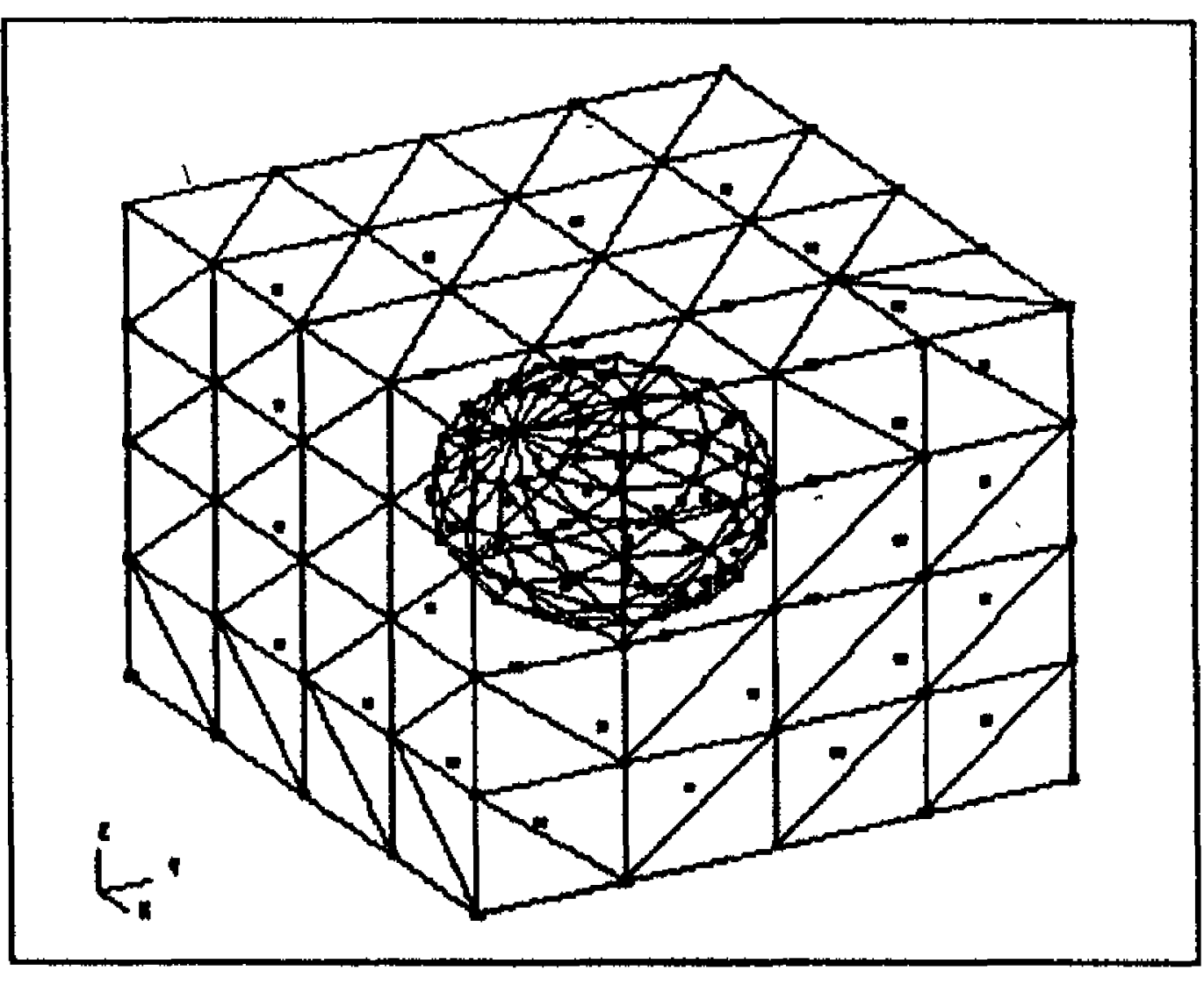

FJGURE 1. CONDUCTJNG SPHERE IN FREE SPACE

Discussion of results: The problem was solved using both first and second order elements. An equipotential plot in the finite element region is shown in figure 3 . The corresponding electric field vectors are shown in figure 4. Due to the large number of unknowns and the large bandwith of the system matrix an option for inclusion of symmetry boundary conditions was added. Figure 5 shows the $1 / 8$ th section of the problem which was solved next. Figure 6 shows the corresponding equipotential plot which is smoother than that of figure 3 due to the smaller size of the elements. Figure 7 shows the potential as a function of radius which agrees well with the analytic solution

$$
V=V_{0}\left(R / R_{0}\right)
$$

Conclusions: The Hybrid method has been successfully extended to three dimensional problems. A solution to a full three dimensional problem was obtained using a relatively small number of unknowns.

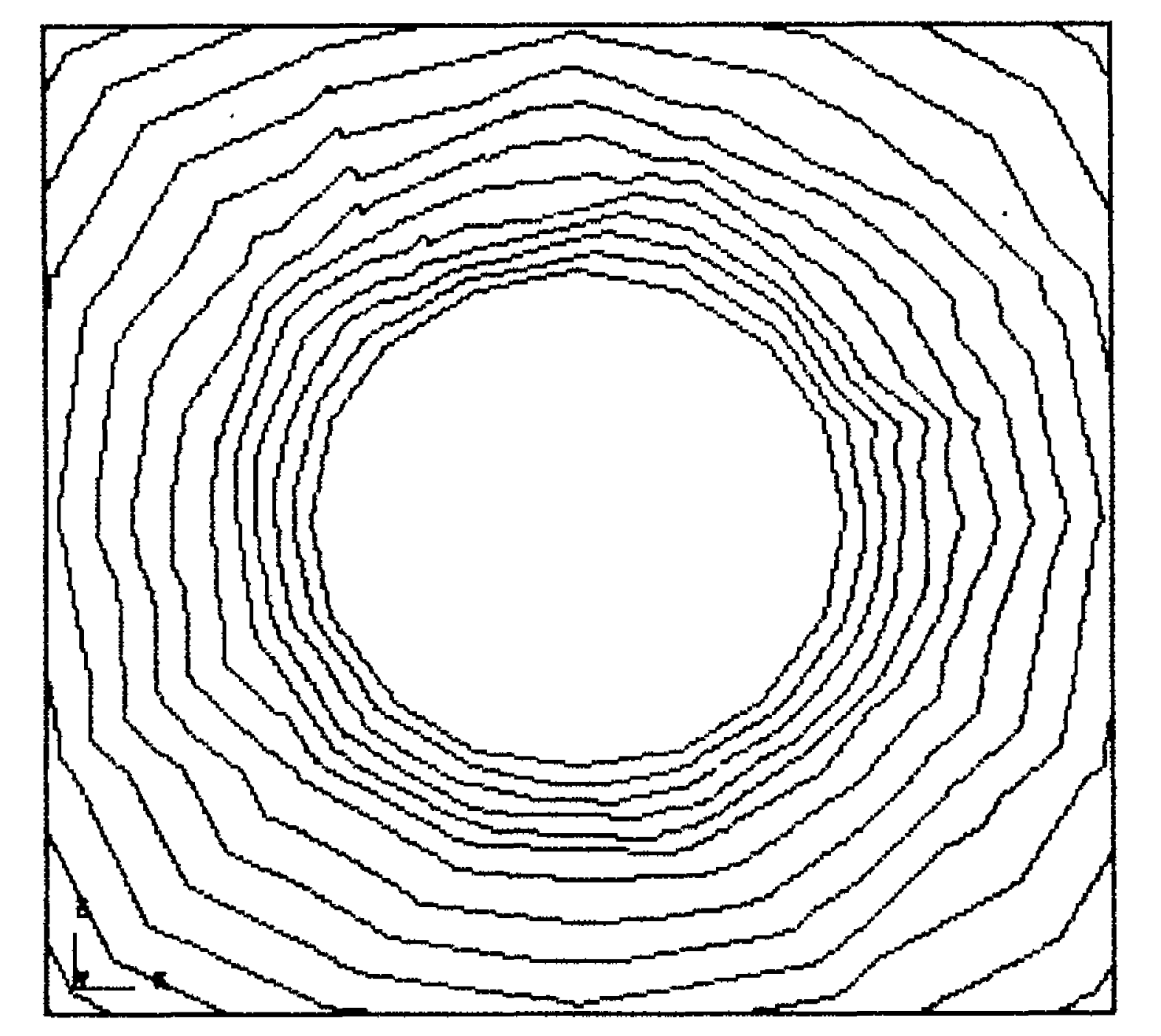

FIGURE 3. EQUTPOTENTIAL PLOT IN THE FINTTE ELEMENT REGION

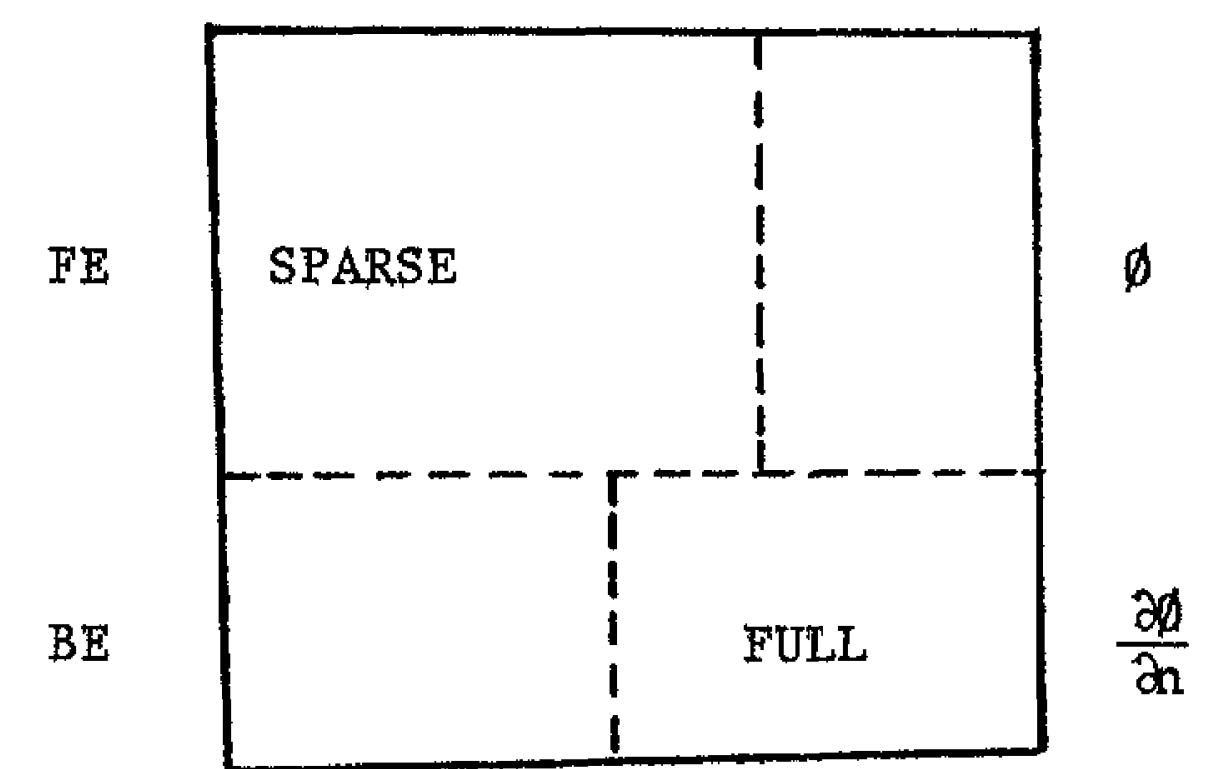

FIGURE 2. FORM OF THF SYSTEM MATRTX

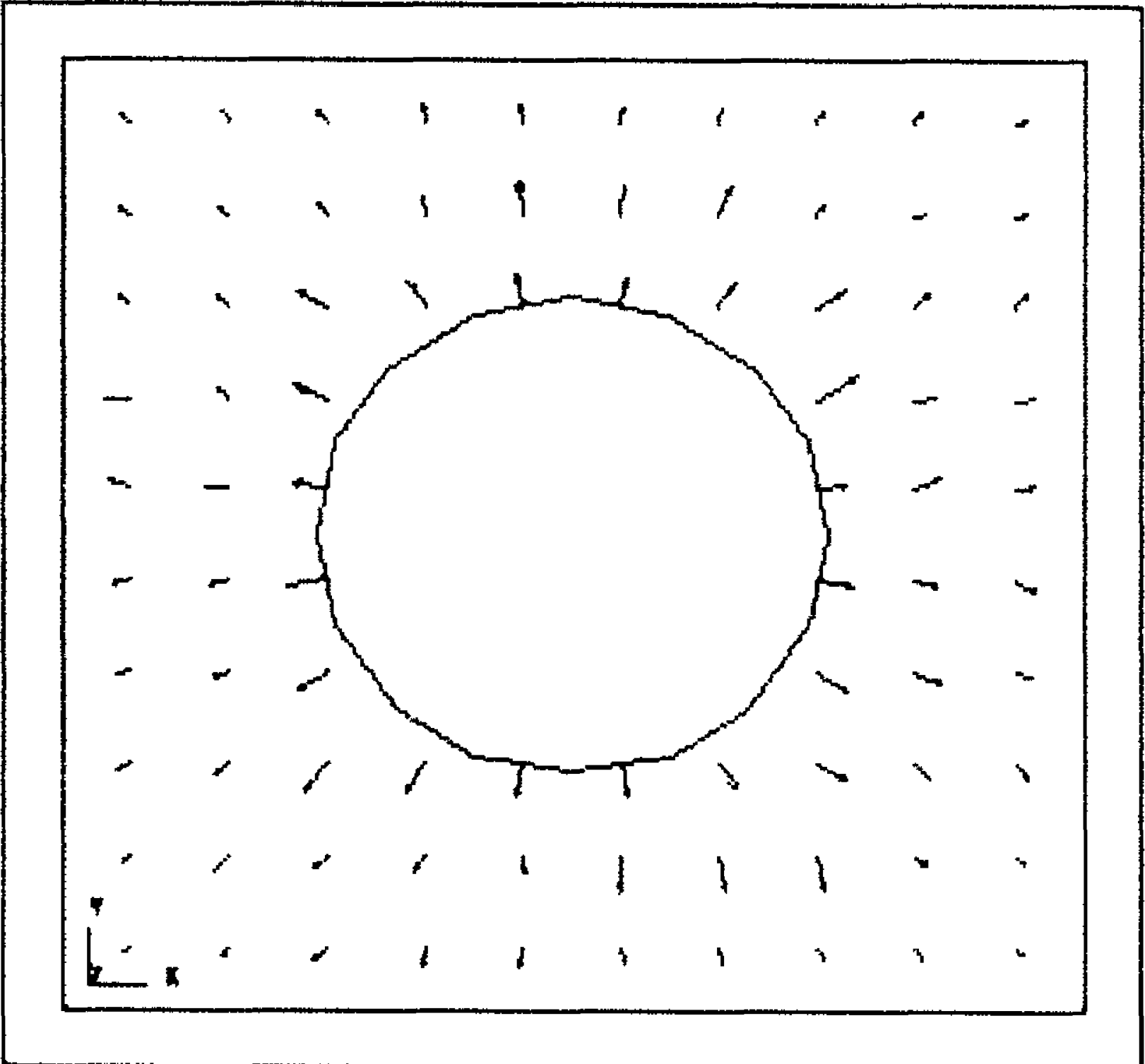

FIGURE 4. ELECTRIC FIELD VECTORS CORRESPONDING TO FIGURE 3

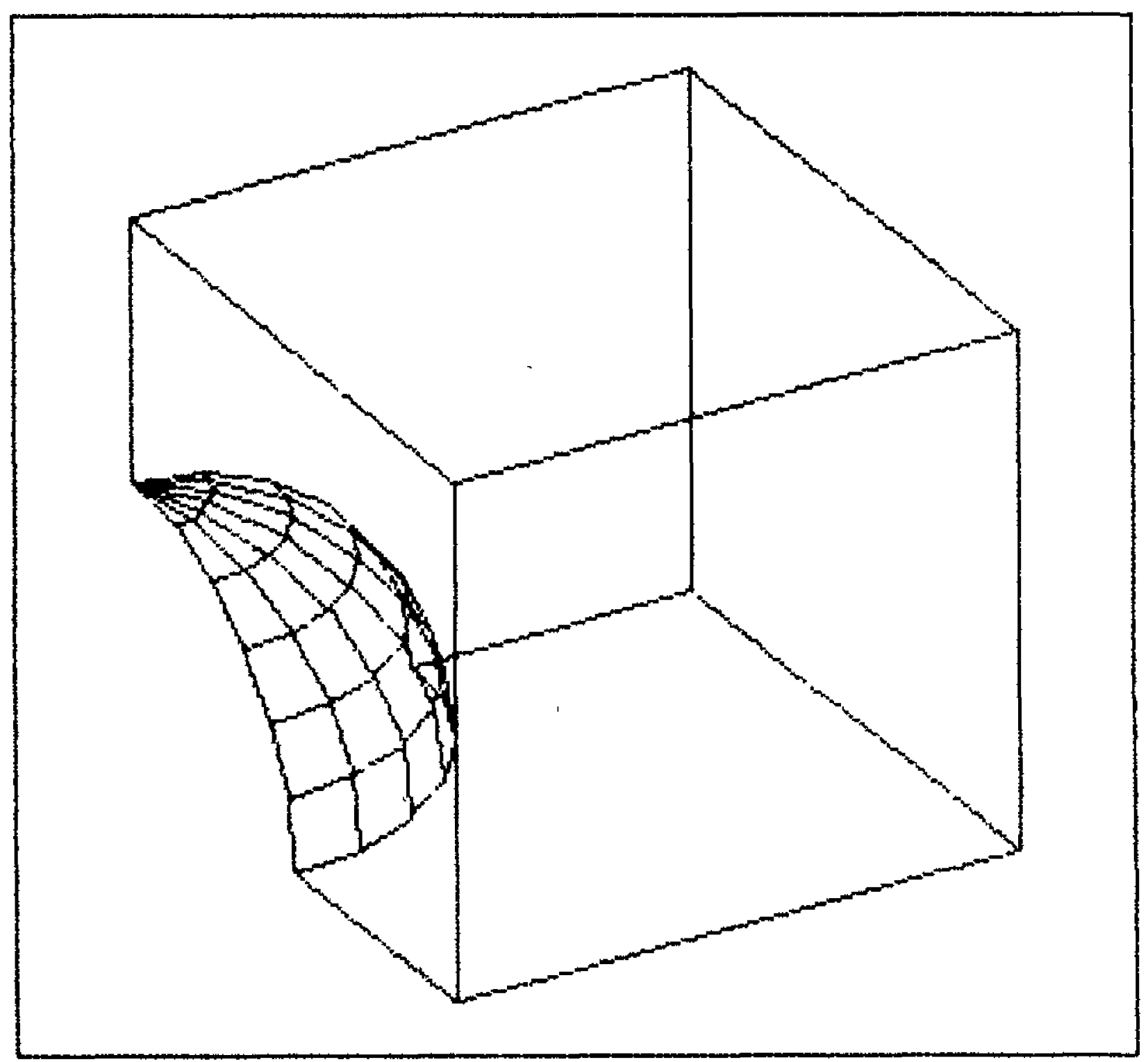

FIGURF 5. SPHFRF, WTTH SYMMETRY CONDITTON 


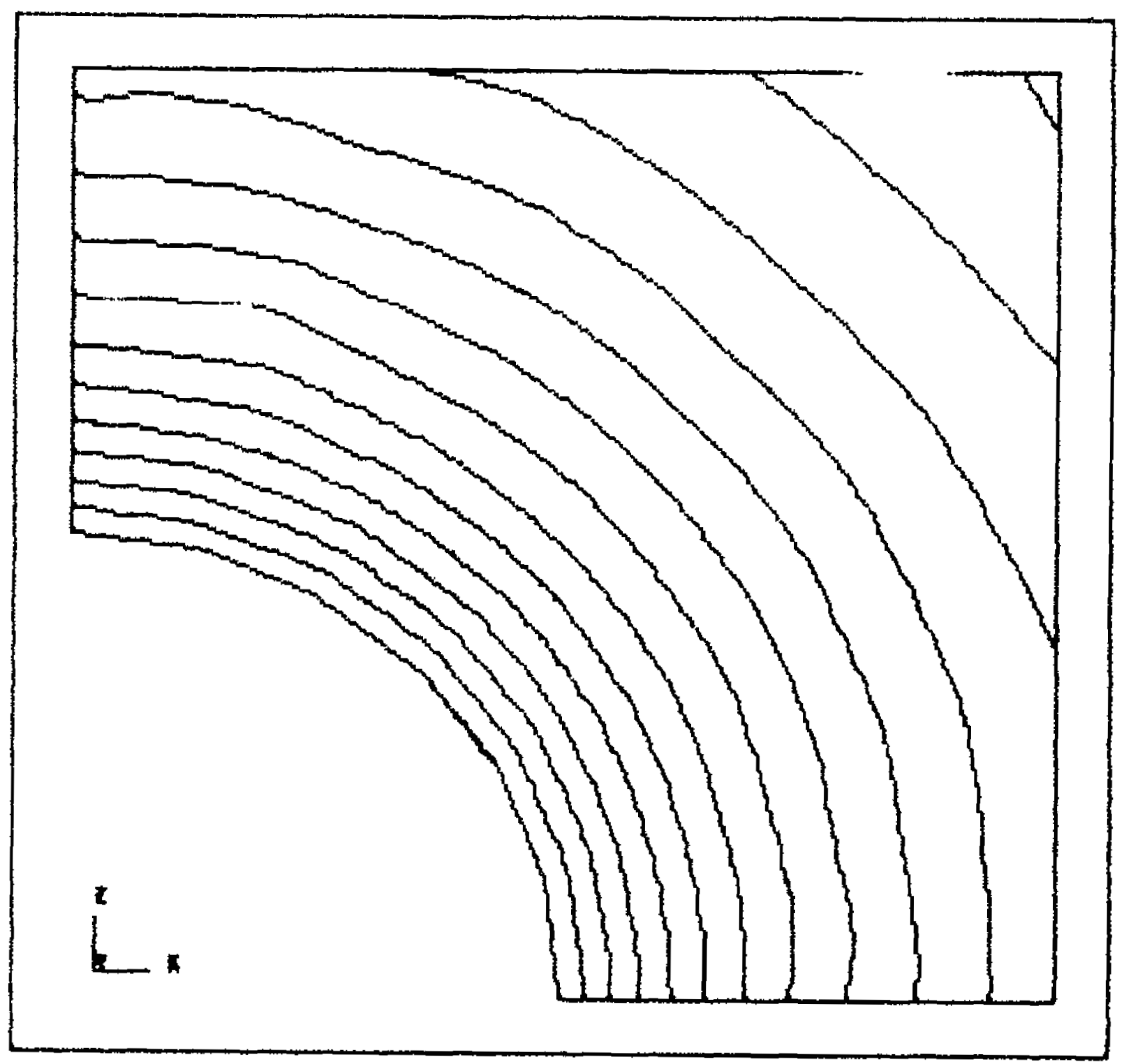

References:

1.S.J.Salon, J.M.Schneider, "A Finite Element Boundary Integral Formulation of Poisson's Equation", IEEE Transactions,Vol.MAG 17.\#6. pp 2574-2576

2.S.J.Salon, J.P.Peng,"A Hybrid Finite Element Boundary Element Formulation of Poisson's Equation For Axisymmetric Vector Potential Problems", J.Appl. Physics 53(11), November 1982 PP 8420-8422

3. S.J.Salon,"The Hybrid Finite Element Boundary Element Method in Electromagnetics", IEEE Trans., Vol.MAG-21, \#5, Sept.1985, pp. 18291834

4.Y. du Terrail, Modelisation Geometrique et Topologique en 3 Dimensions Pour 1'Application de la Method des Elements Finis en Electromagnetism, PhD Thesis INPG Grenoble 1986

5.D.A.H.Jacobs, "Generalizations of the Conjugate Gradient Method for Solving NonSymmetric and

systems", CEGB, RD/L/N70/80

FIGURE 6. EQUIPOTENTIAI, PLOT OF FIGURE 5

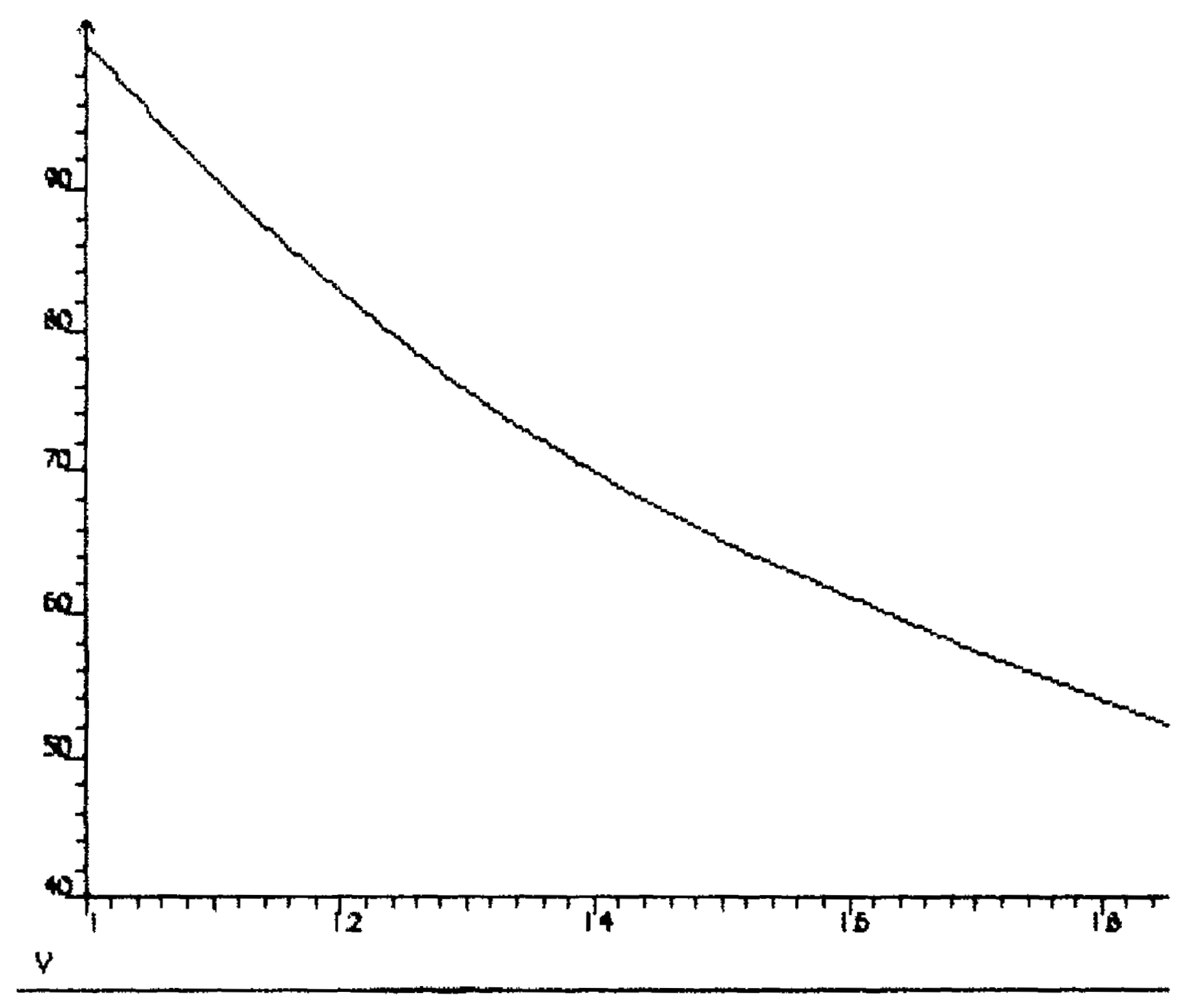

FIGURE 7. POTENTTAL VS. RADIUS TN THF FINITE ELEMENT REGION 